San Jose State University

SJSU ScholarWorks

Master's Theses

Master's Theses and Graduate Research

Fall 2009

\title{
The personality and mental health of physical and social scientists.
}

Chad Richard Kempel

San Jose State University

Follow this and additional works at: https://scholarworks.sjsu.edu/etd_theses

\section{Recommended Citation}

Kempel, Chad Richard, "The personality and mental health of physical and social scientists." (2009). Master's Theses. 4006.

DOI: https://doi.org/10.31979/etd.nkq6-zqyu

https://scholarworks.sjsu.edu/etd_theses/4006

This Thesis is brought to you for free and open access by the Master's Theses and Graduate Research at SJSU ScholarWorks. It has been accepted for inclusion in Master's Theses by an authorized administrator of SJSU ScholarWorks. For more information, please contact scholarworks@sjsu.edu. 


\title{
THE PERSONALITY AND MENTAL HEALTH OF \\ PHYSICAL AND SOCIAL SCIENTISTS
}

\author{
A Thesis \\ Presented to \\ The Faculty of the Department of Psychology \\ San José State University \\ In Partial Fulfillment \\ of the Requirements for the Degree \\ Master of Arts
}

by

Chad Richard Kempel

December 2009 
UMI Number: 1484364

All rights reserved

INFORMATION TO ALL USERS

The quality of this reproduction is dependent upon the quality of the copy submitted.

In the unlikely event that the author did not send a complete manuscript and there are missing pages, these will be noted. Also, if material had to be removed, a note will indicate the deletion.

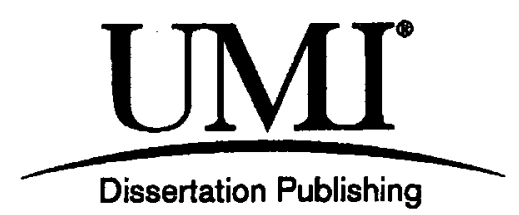

UMI 1484364

Copyright 2010 by ProQuest LLC.

All rights reserved. This edition of the work is protected against unauthorized copying under Title 17, United States Code.

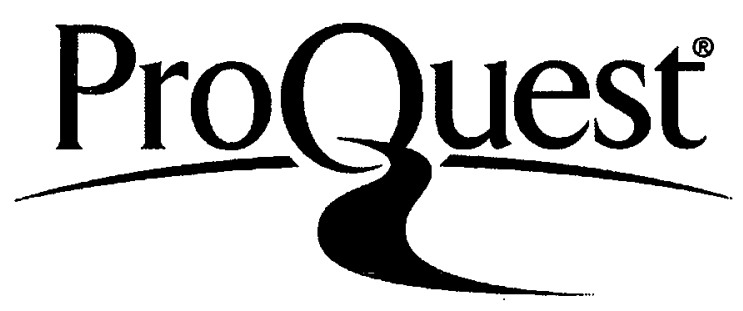

ProQuest LLC

789 East Eisenhower Parkway

P.O. Box 1346

Ann Arbor, MI 48106-1346 
(C) 2009

Chad Richard Kempel

ALL RIGHTS RESERVED 


\section{SAN JOSÉ STATE UNIVERSITY}

The Undersigned Thesis Committee Approves the Thesis Titled

The Personality and Mental Health of Physical and Social Scientists

by

Chad Richard Kempel
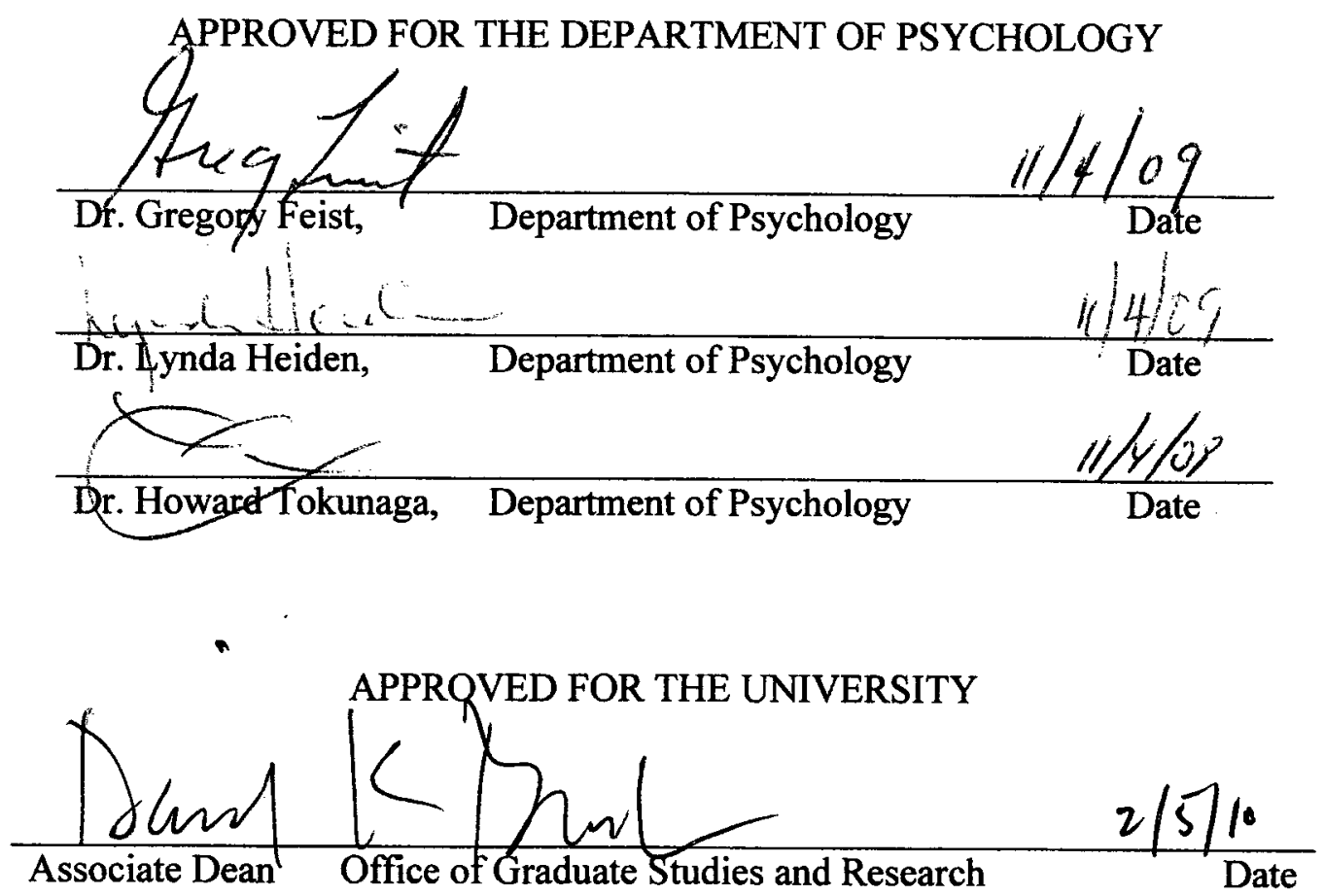


\section{ABSTRACT \\ THE PERSONALITY AND MENTAL HEALTH OF PHYSICAL AND SOCIAL SCIENTISTS \\ by Chad Richard Kempel}

The decision to pursue a career as a scientist and the likelihood of becoming successful is dependent upon a variety of factors, including a unique blend of personality characteristics and mental health. Being either thing- or people-oriented may also be related to whether or not an individual chooses to travel down either the ScienceTechnology-Engineering-Math (STEM) or Social Science path. In order to examine these relationships, 214 academic scientists throughout the United States were assessed on a battery of personality and mental health measures. As was expected, social scientists scored higher than STEM scientists in general on a measure of extraversion. However, STEM scientists in general scored higher than social scientists on an overall measure of autistic characteristics and on specific autistic characteristics' scales. STEM scientists also scored higher than social scientists on the schizotypal trait, cognitive disorganization. Further evidence of the relationships between personality, mental health, and fields of science as well as interpretations and implications of these findings are presented. 


\section{ACKNOWLEDGEMENTS}

First, I want to express my gratitude to my committee chair, Professor Gregory Feist, who has provided me with invaluable knowledge, guidance, and experiences over the past two years. His ambition, enthusiasm, and professional achievements are admirable and have made it an honor conducting research under his guidance. I would also like to thank Dr. Feist for introducing me into the psychology of science and for providing me with the opportunity to contribute to this new field. In addition, a thank you to my committee members, Dr. Lynda Heiden and Dr. Howard Tokunaga, for providing valuable feedback on various psychological and statistical aspects of this project. Furthermore, I want to express my gratitude to my employer, Dr. David Williams, for the guidance, experiences, and flexibility he contributed to this project and to my growth as a researcher.

Thank you to Dr. Ward Rodriguez, Dr. Mary Kay Stevenson, and Dr. Gretchen Reevy, all of California State University, East Bay (CSUEB), for immersing me in various research projects as an undergraduate, providing me with a comprehensive psychological and statistical background, and for the passion for science that they each conveyed during our interactions. Without them I am not sure I would have chosen this path.

For my parents, Paul and Mary, I cannot begin to express the gratitude I have for all that they have provided me over the years. And for my brothers, my best friends, I realize more and more each day just how lucky I was to grow up in the family that we did.

Lastly, I owe my deepest gratitude to my beautiful wife, Amy, for the unconditional love and support she has been giving me since we first met. I love her more each day. 


\section{TABLE OF CONTENTS}

SECTION

PAGE

INTRODUCTION

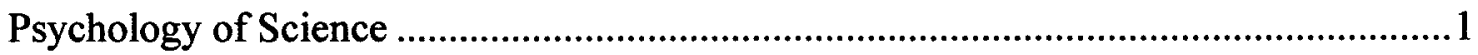

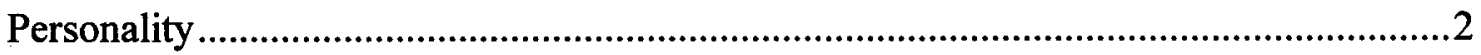

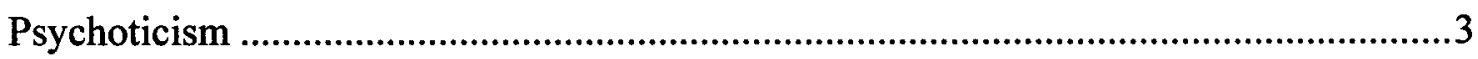

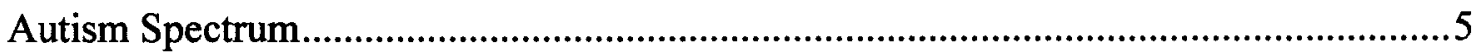

Expanding the Clinical Psychology of Science ...............................................................

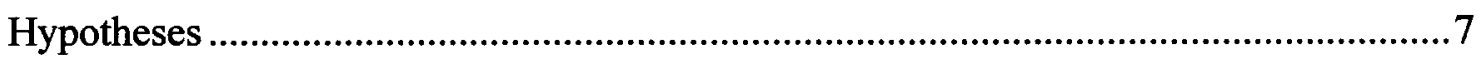

METHOD

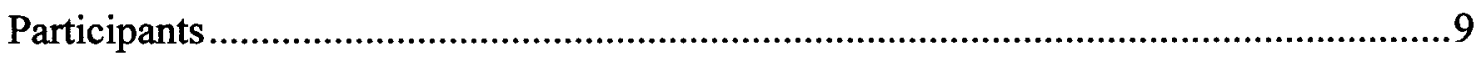

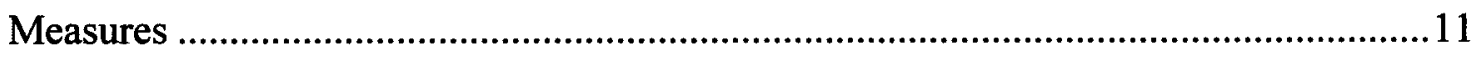

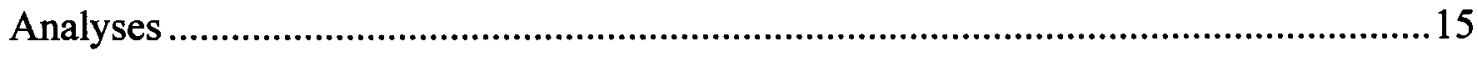

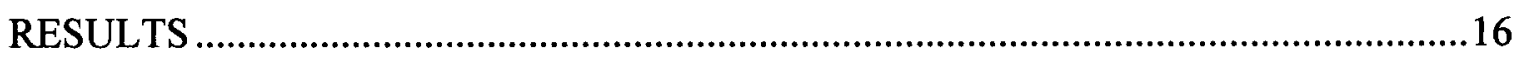

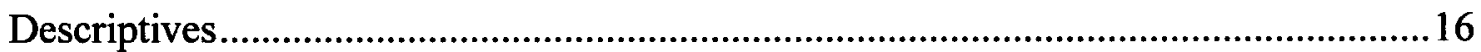

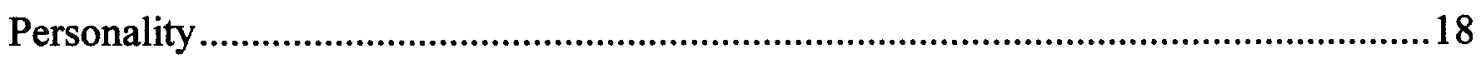

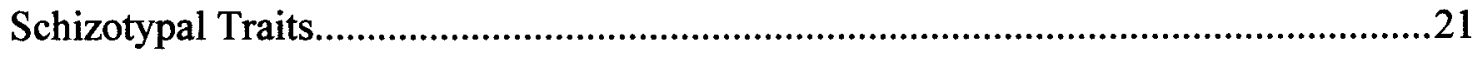

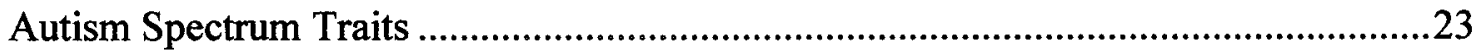

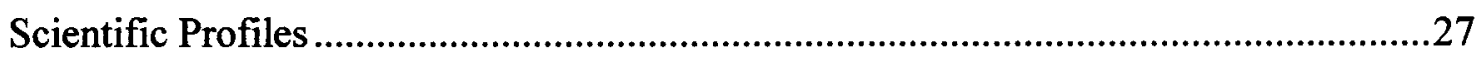

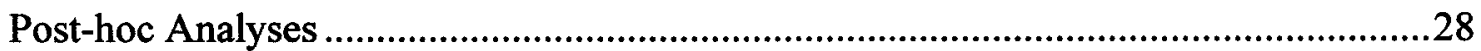

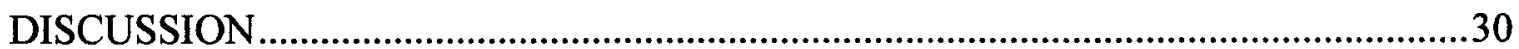


TABLE OF CONTENTS (continued)

SECTION

PAGE

Scientific Profile

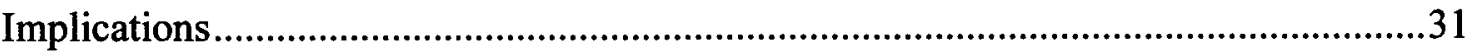

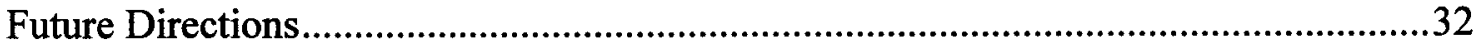

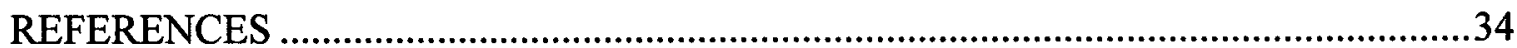

APPENDIX

Appendix. Signed Approval Form...................................................................................39

vii 


\section{LIST OF TABLES}

TABLE

PAGE

1. Demographics by Field of Science .10

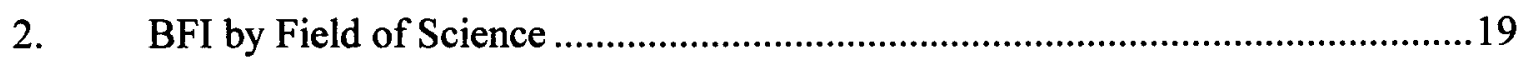

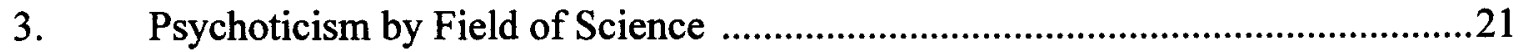

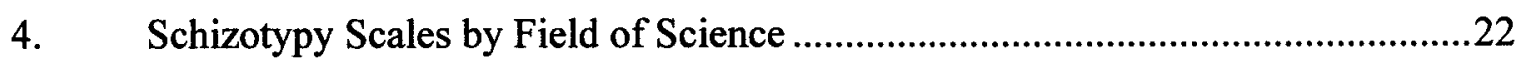

5. AQ Scales and Overall AQ by Field of Science ................................................24 


\section{LIST OF FIGURES}

$\begin{array}{lll}\text { FIGURE } & \text { PAGE }\end{array}$

1. Standardized (z-scores) scale and overall scores by field of science contributing to scientific profiles........................................................................28 


\section{INTRODUCTION}

Psychology of Science

With recent research and excitement being generated within the psychology of science, it is pertinent that the subdisciplines that make up the foundation of this new field be laid out at this early stage. Feist (2006a) describes these major subdisciplines (i.e., developmental, cognitive, personality, social, and biological) as being the psychological factors that drive scientific interest, talent, and achievement but also points out that there is an additional subdiscipline that has yet to be thoroughly empirically investigated, namely clinical psychology of science. Once the clinical psychology of science is better understood, findings can be examined in conjunction with the other driving factors and a more complete psychological profile of scientists can be created. This profile will then provide us with a better understanding of the thought and behavior of scientists, technologists, inventors and mathematicians, which is the aim of this new field of study (Feist, 2008).

Although a general psychological profile of the scientists may well exist, research suggests that within this profile there are two scientific domains that may have distinct profiles, namely, the physical and social sciences (Feist, 2006a, 2006b). The distinction between the physical and social scientist profiles, among other factors, is primarily attributed to the having intellectual gifts in either thing- or people-orientations. Thingoriented individuals tend to be more introverted and interested in molecules, numbers, and other inanimate objects, whereas those who are people-oriented, not surprisingly, are drawn towards social stimuli and tend to be more extraverted (Feist, 2006b; Lippa, 1998; 
Mount, Barrick, Scullen, \& Rounds, 2005; Prediger, 1982). The following study will examine the components of both the physical and social scientific profiles and provide a more comprehensive understanding of each than is currently available.

Personality

Personality can be defined as a pattern of relatively permanent traits, dispositions, or propensities that lend consistency to a person's behavior and thought processes (Feist, J. \& Feist, G.J., 2009). The desire to measure patterns of personality has led to the creation of multiple reliable inventories capable of predicting a variety of criteria (Grucza \& Goldberg, 2007), including mortality (Roberts, Kuncel, \& Shiner, 2007), job performance (Salgado, 2003), well-being (Singh \& Woods, 2008), creativity (Feist, 1998), and mental health (Widiger, 2005). A few examples of how this predictive ability has been utilized include: employers during the selection of job applicants (Hogan, Barrett, \& Hogan, 2007), individuals searching for a partner through online dating services (Houran, Lange, Rentfrow, \& Bruckner, 2004), and clinicians as an aid in diagnosing mental disorders (Cumella, Wall, \& Kerr-Almeida, 2000).

Personality also appears to be one of the strongest and most reliable predictors of scientific interest and talent, along with intelligence and demographics (Feist, 2006a, 2006b). The complete profile of a scientist, however, remains deficient and is likely to remain so until larger inventories of intellectual and scientific talent surface (Simonton, 2008). As mentioned above, one main area missing in the psychology of science is a clinical/mental health perspective. The most promising clinical dimensions associated with scientific interest and talent appear to be psychoticism (Feist, 1998; Simonton, 
2008), schizotypy (Nettle, 2006), and autism (Feist, 2006a, 2006b). These aspects of mental health among scientists in different domains, along with personality, will be the primary concern of the present study. In short, this study aims to fill that gap in the psychology of science.

\section{Psychoticism}

Psychoticism, one of the three dimensions of Eysenck's model of personality (i.e., psychoticism, extraversion, and neuroticism), is a dispositional trait that increases the susceptibility of developing psychotic symptoms but should not be confused with psychosis (i.e., a psychopathological state; Eysenck, S. G., White, \& Eysenck, H. J., 1976; Eysenck, 1993). Elevated levels of psychoticism tend to be characterized by social isolation, aloofness, hostility, unusual thoughts and behaviors, and creativity. In the current study, psychoticism will be defined in terms of the psychoticism scale of the Eysenck Personality Questionnaire (EPQ). The psychoticism scale measures a personality dimension that predisposes those scoring high on the scale to psychotic-type disorders (Eysenck, S. G., White, \& Eysenck, H. J., 1976).

The link between scientific creativity and psychoticism is one that has been explored extensively over the years but continues to elicit new and exciting research and interpretations (Barron, 1963; Batey \& Furnham, 2008; Kokosh, 1969; Ludwig, 1995; Nettle, 2006; Post, 1994; Simonton, 1999). Historically, research has demonstrated a link between psychoticism and creativity, especially in artists and the general population (Eysenck, 1995; Feist, 1998; Ludwig, 1995). Results, however, have been mixed and these inconsistent results have lead some researchers to propose that psychoticism is too 
broad and general and, in fact, its relationship to scientific creativity would be better understood if broken down into specific components, such as latent inhibition and schizotypy (Batey \& Furnham, 2008; Mason, Claridge, \& Jackson, 1995).

Latent inhibition. Latent inhibition (LI) is the ability to filter irrelevant stimuli (Eysenck, 1995; Lloyd-Evans, Batey, \& Furnham, 2006; Lubow, 1989) and research suggests that LI may be a key link between psychoticism and scientific creativity (Eysenck, 1995). If an individual has low LI, they are incapable of or have a lessened ability to filter out irrelevant stimuli (Lubow, 1989). Whereas in those with mental disorders, a bombardment of irrelevant stimuli can lead to intense sporadic thoughts, excessive speech, and distractibility (Kusumakar, Bond, \& Yatham, 2002), this same bombardment can lead to an increase in creative thought and achievement in individuals who are mentally stable (Eysenck, 1995; Feist, 2006a). However, having low LI as an underlying factor in creative achievement also leaves open the possibility of residual psychotic characteristics in one's personality.

Both low LI and the residual psychotic features are not dispersed evenly throughout the scientific domains, however. Research shows that fields of science for which subjectivity, meaning, and value are emphasized tend to have a higher lifetime prevalence of psychopathology than those fields that rely on mathematics, precision, and objectivity (Ludwig, 1998).

Schizotypy. Schizotypy is another characteristic that is unequally distributed among the fields of science (Batey \& Furnham, 2008; Nettle, 2006) and is argued by some to be a dimension of personality (Mason, Claridge, \& Jackson, 1995). 
Characterized by traits similar to borderline personality disorder (Mason, Claridge, \& Jackson, 1995), schizotypy is a psychological concept thought to exist on a continuum in the general population and includes the following traits: unusual experiences (i.e., hallucinatory and/or magical thinking), cognitive disorganization (i.e., difficulty concentrating, feelings of worthlessness, and social anxiety), introvertive anhedonia (i.e., lack of enjoyment), and impulsive nonconformity (i.e., violent and self-abusive behaviors; Mason, Claridge, \& Jackson, 1995). Often, schizotypy is measured using the Oxford-Liverpool Inventory of Feelings and Experiences (O-LIFE; Mason, Claridge, \& Jackson, 1995; Nettle 2006).

Researchers have reported that mathematicians tend to have lower levels of unusual experiences, cognitive disorganization, and impulsive nonconformity than do non-mathematicians (Nettle, 2006). Mathematicians, however, do tend to score higher on measures of mental disorders characterized by systematic and convergent thinking, such as autism (Baron-Cohen, Wheelwright, Skinner, Martin, \& Clubley, 2001; Feist, 2006b, Nettle, 2006).

Autism Spectrum

According to the American Psychiatric Association (DSM-IV-TR), autism is a pervasive developmental disorder characterized by "the presence of markedly abnormal or impaired development in social interaction and communication" $(2000, \mathrm{p} .70)$ and "restricted repetitive and stereotyped patterns of behavior, interests, and activities," (2000, p. 75$)$ which begin prior to three years of age. Although strict guidelines are in place for diagnosing autism, there has been a recent shift towards the idea that the 
disorder exists on a spectrum of social-communication disability ranging from autism to average and above average, with Asperger's syndrome (AS) falling somewhere inbetween (Baron-Cohen et al., 2001).

AS is also a pervasive developmental disorder and is characterized by the same "restricted repetitive and stereotyped patterns of behavior, interests, and activities" (p. 75) as autism, but without delays in language, curiosity, and cognitive development (American Psychiatric Association, 2000). In the current study, we embrace the spectrum theory and will assess where individuals are situated along the continuum using a self-administered instrument developed by Baron-Cohen and colleagues (2001) that assesses autistic spectrum traits in individuals with average or above average intellect.

The idea of autistic-like characteristics being possessed by non-diagnosed individuals is in the early stages of being examined but is producing interesting results. Baron-Cohen and colleagues (2001) reported that those studying mathematics tend to have a greater number of autistic-like tendencies than those studying other scientific fields, particularly the social sciences. Austin (2005) replicated the findings of BaronCohen and colleagues (2001) and provided evidence that an increase in autistic characteristics among mathematicians and those in physical sciences is associated with introversion, a characteristic correlated with autism spectrum traits (Wakabayashi, BaronCohen, \& Wheelwright, 2006). The study of autistic qualities is a relatively new addition to the mental health aspect of profiling scientists and the present study attempts to create a more concise understanding of this relationship. 
Expanding the Clinical Psychology of Science

The current study also expands on the earlier work of Kokosh $(1969,1971,1976)$, Nettle (i.e., scientists limited to only mathematicians; 2006), Norman and Redlo (1952), and Post (1994) by using a sample of academic scientists in various scientific fields across all geographic regions of the United States so that the findings are more generalizable. Many of these studies, however, were limited to student samples. The present study, therefore expands on early research (Austin, 2005; Kokosh, 1969, 1971, 1976; Nettle, 2006; Norman \& Redlo, 1952) by assessing these traits in professional scientists and by administering multiple measures of mental health and personality simultaneously so that more comprehensive scientific profiles can be created. Once a comprehensive profile exists, necessary steps can be taken to facilitate the enhancement of one's potential through education, experience, and guidance into and within specific fields of study (Simonton, 2009).

\section{Hypotheses}

We predict that there will be a linear relationship between scientists' personality and their interests or involvement in distinct domains of science. Specifically, we expect individuals in the physical sciences (including engineering and computer science) to score higher on measures of autistic spectrum traits than those in the social sciences (Austin, 2005; Nettle, 2006). Additionally, we predict that individuals in the social sciences will score higher on measures of schizotypy and psychoticism (Ludwig, 1995, 1998) than those in the physical sciences. Lastly, we predict that individuals in the social 
sciences will score higher on measures of extraversion than those in the STEM sciences

(Austin, 2005; Kokosh, 1969, 1976). 


\section{METHOD}

\section{Participants}

Sampling and procedure. The first step in selecting participants was to select universities from which we could solicit participation. Using an online database, The Carnegie Classification of Institutions of Higher Education ${ }^{\mathrm{TM}}$ (The Carnegie Foundation for the Advancement of Teaching, 2008), we randomly selected four universities classified as high research activity from each of the four United States Census regions (i.e., West, Midwest, Northeast, and South; U.S. Census Bureau, 2008). Within each of these 16 universities, we identified science and engineering departments within each of the National Science Foundation's (NSF; San Diego Supercomputer Center, 2008) identified fields of sciences that were targeted for participation [i.e., Mathematical and Physical (i.e., Physics and Chemistry), Computer and Information (i.e., Computer Science), Biological (i.e., Biology), Social, Behavioral, and Economic (i.e., Psychology, Sociology, and Anthropology), Geosciences (i.e., Geological-Earth), and Engineering (i.e., Civil and Mechanical Engineering).

We selected all faculty within each of these departments for participation in the online study who were indicated on their departmental webpage as being on the tenure track and who had a visible e-mail address on their university's website. In spring of 2009 , we sent a total of 3,183 individuals an e-mail containing a description of the study and an invitation to participate (see Appendix A). We sent prospective participants a follow-up request to participate two weeks after the initial request and gave all participants at least one month to complete the battery of measures. We instructed 
willing participants to follow a hyperlink embedded in the e-mail that directed them to the electronic survey, which was hosted by the web-based survey and evaluation system SurveyMonkey. The electronic survey began with a notice of consent and we informed participants that involvement would take approximately 15 to 20 minutes; however, an unlimited amount of time was given to complete the measures.

Sample. Of the 3,183 participants solicited, a total of $318(10 \%)$ responded to the initial invitation, 38 of whom were removed from the dataset because they did not complete at least one of the measures, and 23 of whom were removed because they did not indicate which field of science they were associated with. Forty-three biologists responded but were not included in the analyses because doing so was beyond the scope of this study. The remaining 214 participants ( 144 males, 68 females, and 2 not reported) were between 24 and 81 years of age $(M=49.26, \mathrm{SD}=13.11)$. A breakdown of age and gender by field of science is presented in Table 1 .

Table 1

Demographics by Field of Science

\begin{tabular}{lccccccc}
\hline & \multicolumn{3}{c}{ Age } & & \multicolumn{3}{c}{ Gender } \\
\cline { 2 - 4 } \cline { 6 - 8 } Sciences & $n$ & $M$ & $S D$ & & Male & Female & Not Reported \\
\hline STEM & 122 & 48.94 & 13.62 & & 91 & 31 & 1 \\
Physical & 73 & 47.53 & 13.45 & & 54 & 20 & 0 \\
Engineering & 28 & 53.11 & 14.65 & & 21 & 6 & 1 \\
Computer & 21 & 48.29 & 12.19 & & 16 & 5 & 0 \\
Social & 89 & 49.70 & 12.46 & & 53 & 37 & 1 \\
\hline
\end{tabular}


Grouping. We grouped participants according to the field of science with which they most closely identified. During analysis, we condensed the NSF fields of science into four parent fields (i.e., Social Science was made up of Psychology, Sociology, and Anthropology; Engineering was comprised of Civil and Mechanical Engineering; Physical Science included Physics, Chemistry and Geological-Earth; Computer Science was its own field; Biology was not included in the analyses because it was beyond the scope of this analysis) in order to address the research questions.

For certain analyses, we further grouped these four fields into two overarching areas of science, Science-Technology-Engineering-Math (STEM) sciences (i.e., Physical Science, Computer Science, and Engineering) and Social Sciences. The logic behind creating these two overarching areas is tied back to our tendency to be either thing- or people-oriented (Feist, 2006a, 2006b), which describes STEM and social scientists, respectively.

Measures

Big Five Personality Inventory (BFI). The Big-Five Model of personality is the most prominent and heuristic model of personality in psychology (Zhang, 2002). We assessed the Big Five personality dimensions using an empirically created 44-item selfreport measure (John, Donahue, \& Kentle, 1991). Five factors of personality are derived from the items, including extraversion, agreeableness, conscientiousness, neuroticism, and openness. Participants were instructed to indicate the extent to which they agree or disagree with each of the items using a Likert scale. Oliver and Srivastava (1999) have 
reported alpha reliability coefficients ranging from .80 to .90 for BFI's administered three months apart.

Revised Eysenck Personality Questionnaire - Abbreviated (EPQR-A). The EPQR-A is a 24-item instrument that measures personality along three scales (i.e., extraversion, neuroticism, psychoticism) and also provides a lie score that determines the accuracy and consistency of responses (Francis, Brown, \& Philipchalk, 1992).

Participants were instructed to answer either "yes" $(1)$ or "no" $(0)$ to a series of questions and their responses were later summed to create a composite score for each of the scales, ranging from 0-6.

Reliability of the scales has been assessed by Francis, Brown, and Philipchalk (1992), with alpha coefficients ranging from .52 (psychoticism) to .84 (extraversion). Leslie and Katz (2000) assessed the concurrent validity of the EPQR-A with the parent of the measure, the shortened Eysenck Personality Questionnaire (EPQR-S; Eysenck, H. J., Eysenck, S. B. G., \& Barrett, 1985), and attained correlation coefficients ranging from .80 (psychoticism) to $.94-.95$ (neuroticism and extraversion, respectively). When concurrent validity with the original Eysenck Personality Questionnaire (EPQ) is assessed, correlations range from .84 to .90 for the extraversion and neuroticism scales and up to .52 for the psychoticism scale (Francis, Brown, \& Philipchalk, 1992). Francis, Brown, and Philipchalk (1992) state that the lower correlation between the EPQR-A and the EPQ is due to an intentional modification of the psychoticism construct. Research shows that concurrent validity among the EPQ scales and external measures of similar constructs are also strong (Zumbo \& Taylor, 1993). The extraversion scale of the EPQ 
and the Myers-Briggs Type Indicator extraversion scale are highly correlated $(r=-.83$; Zumbo \& Taylor, 1993), the EPQ neuroticism scale shows a strong correlation with Dutch Personality Questionnaire $(r=.78$; Barelds \& Luteijn, 2002), and the EPQ psychoticism scale is correlated with the Narcissistic Personality Inventory $(r=.23$; Raskin \& Hall, 1981), although weakly.

Oxford-Liverpool Inventory of Feelings and Experiences - Shortened) (O-LIFES). The O-LIFE-S consists of 43 yes/no items that comprise four schizotypy scales (i.e., unusual experiences, cognitive disorganization, introvertive anhedonia, and impulsive nonconformity; Mason, Linney, \& Claridge, 2005). Internal consistency of the items in each scale were assessed and all exceeded an alpha coefficient of .60 (Mason, Linney, \& Claridge, 2005). Mason, Linney, and Claridge (2005) also assessed the concurrent validity of the O-LIFE-S with a longer version of the measure (i.e., O-LIFE) and attained correlation coefficients above .90 for all scales. Furthermore, Mason and Claridge (2006) thoroughly reviewed the vast array of literature spanning multiple domains that have made use of this measure of schizotypy, providing support for the construct validity of the O-LIFE-S.

Autism-Spectrum Quotient (AQ). The AQ is a 50-item instrument that measures the degree to which an adult with average or above average intelligence has the traits associated with autistic spectrum disorders (Baron-Cohen et al., 2001). Five scales are derived from the $\mathrm{AQ}$, including social skills, attention switching, attention to detail, communication, and imagination. An overall AQ score is produced by summing the scores across all scales. Each scale ranges from 1-10, overall AQ scores range from 5-50, 
and an overall score of 32 or greater is the cutoff for identifying clinically significant levels of autistic spectrum traits (Baron-Cohen et al., 2001). Baron-Cohen and colleagues (2001) chose 32 as the cutoff because in their base sample the majority (79.30\%) of adults with AS scored at or above this level, while only $2 \%$ of adults without AS did so.

Internal consistency of the items in each scale have been assessed by BaronCohen and colleagues (2001) using Cronbach's alpha (social skills $=.77$, attention switching $=.67$, attention to detail $=.63$, communication $=.65$, and imagination $=.65$ ) and the internal consistency of the overall AQ scale was assessed at $r=.82$ (Austin, 2005). Baron-Cohen and colleagues (2001) successfully demonstrated test-retest reliability of $r=.70(p=.002)$ over a two week period. Construct validity of the AQ was established by having a clinician blindly assess the number of autism spectrum traits that high AQ scorers have using the Diagnostic and Statistical Manual of Mental Disorders (DSM-IV; American Psychiatric Association, 1994), with 64\% accuracy in determining which individuals scored 32 or greater on the overall $A Q$ (Baron-Cohen et al., 2001; Baron-Cohen, Wheelwright, Robinson, \&Woodbury-Smith, 2005). Concurrent validity of the AQ-was also successfully demonstrated in a clinical sample-using the Adult Asperger Assessment, a tool for assessing AS (Baron-Cohen et al., 2005). In BaronCohen and colleagues study, 34 adults diagnosed with AS and eight adults not diagnosed with $\mathrm{AS}$ completed the $\mathrm{AQ}$ and those diagnosed with $\mathrm{AS}$ scored significantly higher than those without the diagnosis, $t(40)=-2.5, p=.015)$. Participants in their study also completed the Empathy Quotient, another measure believed to assess individuals on 
autistic characteristics, and the two groups again were differentiated, $t(40)=3.1, p=$ $.004)$, such that those diagnosed with AS scored higher than those who did not have the diagnosis.

Demographic Questionnaire. In addition to completing the above measures, we asked participants a series of questions about themselves, including their age, gender, race, and the area of science with which they most closely identified with. Other information that we collected includes region of residence within the United States, highest level of education completed, and the highest degree awarded at their affiliated university. Analyses

Separate one-way analysis-of-variances (ANOVA) were conducted to evaluate the relationship between the overarching fields of science (i.e., STEM and social sciences) and the multiple scale and the composite scores of each of the psychological variables (personality, traits associated with autistic characteristics, and schizotypal characteristics). Again, we predicted that physical (i.e., STEM) scientists would score higher than social scientists on measures of autistic traits and lower on extraversion, psychoticism, and schizotypy. Alpha was set at .05 for all analyses. 


\section{RESULTS}

Descriptives

Geographic region. To ensure that geographic region did not influence the responses to our measures these relationships were assessed by conducting omnibus analysis of variance (ANOVA) tests for each scale/dimension by geographic region. All scale and dimension scores, except the attention switching scale of the $\mathrm{AQ}, F(3,203)=$ $4.51, p<.01$, were not differentiated by geographic region, $p>.05$. It is important to note that although the relationship between region and attention switching was significant, pairwise comparisons between the significantly different regions (i.e., Northeast versus both West and South) yielded small effect sizes, $d<.08$ (Cohen, 1992).

Grouping. In order to justify grouping Psychology, Sociology, and Anthropology into the overarching field of Social Science, separate omnibus ANOVAs were conducted for each measure scale and the overall AQ score by each of these fields of science to ensure that they were statistically similar. Psychology, Sociology, and Anthropology were statistically similar on all of the BFI, EPQR-A, and O-LIFE-S dimensions and scales, $p>.05$, except on the unusual experiences, $F(2,88)=4.49, p<.05$, and introvertive anhedonia scales, $F(2,84)=4.33, p<.05$, of the O-LIFE-S. An examination of the pairwise comparisons revealed that the only difference on the unusual experiences scale was between anthropologists $(M=2.81, S D=2.97)$ and sociologists $(M=1.11, S D=1.20), t(82)=1.71, p<.05, d=.54$. Similarly, pairwise comparisons revealed that the only difference on the introvertive anhedonia scale was between 
anthropologists $(M=3.53, S D=2.88)$ and sociologists $(M=1.56, S D=1.29), t(82)=$ $1.97, p<.05, d=.64$

Psychology, Sociology, and Anthropology were also statistically similar on all of the AQ scales, $p>.05$, except attention switching, $F(2,87)=4.04, p<.05$. An examination of the pairwise comparisons revealed that the only difference on the attention switching scale was again between anthropologists $(M=5.50, S D=2.00)$ and sociologists $(M=4.26, S D=1.68), t(85)=1.52, p<.05, d=.48$.

Therefore, due to the statistical differences and large effect sizes (Cohen, 1992) between Anthropology and the other Social Sciences, anthropologists were not included in the Social Science group for the subsequent analyses of the unusual experiences, introvertive anhedonia, and attention switching scales. In addition, due to the contribution of the attention switching scale to the overall AQ score, anthropologists were not included in the analysis of this composite score.

In order to justify grouping Physical Science, Computer Science, and Engineering into the overarching STEM science field, separate omnibus ANOVAs were conducted for each measure scale and the overall $A Q$ score by each of these fields of science to ensure that they were statistically similar. Physical Science, Computer Science, and Engineering were statistically similar on all of the EPQR-A, O-LIFE-S, and AQ dimensions and scales, $p>.05$. However, there were differences between these groups within the BFI agreeableness, $F(2,122)=4.00, p<.05$, and conscientiousness dimensions, $F(2,118)=$ $3.29, p<.05$. Pairwise comparisons within the agreeableness dimension revealed that 
engineers $(M=4.18, S D=.42)$ scored higher than physical $(M=3.86, S D=.63), t(120)$ $=.32, p=.05, d=.07$, and computer scientists $(M=3.74, S D=.64), t(120)=.44$, $p<.03, d=.13$. Within the conscientiousness dimension, physical scientists $(M=3.96$, $S D=.61)$ scored significantly higher than computer scientists $(M=3.59, S D=.57)$, $t(116)=.38, p<.05, d=.09$.

Therefore, due to the small effect sizes (Cohen, 1992) between the abovementioned groups on the agreeableness and conscientiousness dimensions, we proceeded as planned and grouped Physical Science, Computer Science, and Engineering in to the overarching STEM Science field. However, caution was used during the interpretation of the analyses corresponding to these dimensions.

\section{Personality}

Extraversion. Again, we expected social scientists to score higher than STEM scientist subsets and in STEM scientists in general on the extraversion dimension of the BFI. An ANOVA was conducted examining the effect of scientific field on extraversion, as measured by the BFI, but the results were not significant, $F(3,207)=1.74, p>.05$. However, in support of our prediction, when carrying out the planned comparisons we found that social scientists $(M=3.48, S D=.86)$ scored significantly higher (a higher score indicates a greater degree of extraversion) than physical scientists $(M=3.19, S D=$ .80 ) on this dimension, $t(204)=2.16, p<.05, d=.34$ (see Table 2). In addition, there was a trend for the social scientists to score higher than the STEM scientists $(M=3.25$, $S D=.83$ ), although this relationship was not significant, $t(204)=1.67, p=.10, d=.30$. 
Table 2

BFI by Field of Science

STEM Physical Engineering Computer Social

Extraversion

$n$

118

27

21

90

M

3.25

3.19

3.27

3.45

3.48

$S D$

.83

.80

.87

.86

.86

Agreeableness

$\begin{array}{lccccc}n & 123 & 74 & 28 & 21 & 87 \\ M & 3.91 & 3.86 & 4.18 & 3.74 & 3.70 \\ S D & .61 & .63 & .42 & .64 & .71\end{array}$

Conscientiousness

n

M

$S D$

Neuroticism

$\begin{array}{lrrrrc}n & & & & & \\ M & 121 & 73 & 27 & 21 & 85 \\ M & 2.60 & 2.59 & 2.35 & 2.93 & 2.66 \\ S D & .87 & .86 & .79 & .93 & .72\end{array}$

119

3.90

3.96

.63

.61

.65

.57

.67

21

87

3.59

4.05

3.97

57

\section{Openness}

n

122

73

28

21

91 
Table 2 (continued)

\begin{tabular}{lrcccc}
\hline & STEM & Physical & Engineering & Computer & Social \\
\cline { 2 - 6 }$M$ & 4.07 & 4.07 & 4.13 & 4.01 & 3.99 \\
$S D$ & .53 & .52 & .58 & .51 & .66 \\
\hline
\end{tabular}

Agreeableness. An omnibus ANOVA was conducted yielding a significant effect of scientific field on agreeableness, $F(3,209)=4.10, p<.01$. Engineers in particular $(M=4.18, S D=.42)$ scored significantly higher (a higher score indicates a greater degree of agreeableness) than social scientists $(M=3.70, S D=.71)$ on agreeableness, $t(78.20)=$ 4.33, $p<.001, d=.94$ and STEM scientists in general $(M=3.91, S D=.61)$ scored significantly higher than social scientists, $t(133.21)=1.94, p=.05, d=.27$.

Conscientiousness. An omnibus ANOVA was conducted yielding a significant effect of scientific field on conscientiousness, $F(3,209)=2.95, p<.01$. Social scientists $(M=4.05, S D=.67)$ scored significantly higher (a higher score indicates a greater degree of conscientiousness) than computer scientists $(M=3.59, S D=.57)$ on this dimension, $t(202)=2.97, p<.01, d=.72$. Likewise, social scientists scored significantly higher than STEM scientists in general $(M=3.90, S D=.63)$ on this dimension, $t(202)=2.58$, $\mathrm{p}<.05, d=.36$.

Neuroticism. There was no significant difference among the scientific fields on neuroticism, $F(3,205)=2.21, p>.05$. However, there was a trend for the social scientists $(M=2.66, S D=.72)$ to score higher (a higher score indicates a greater degree of neuroticism) than the engineers $(M=2.35, S D=.93), t(202)=1.76, p=.08, d=.39$. 
Psychoticism. Again, we expected social scientists to score higher than STEM scientist subsets and STEM scientists in general on the psychoticism scale. There was not a significant difference among the scientific fields on the psychoticism dimension, $F(3,203)=1.20, p>.05$. However, there was a trend for the social scientists $(M=3.08$, $S D=.80$ ) to score higher (a higher score indicates a greater degree of psychoticism) than the engineers in particular $(M=2.74, S D=.86), t(200)=1.83, p=.08, d=.40$, and the STEM scientists in general $(M=2.90, S D=.86), t(200)=1.64, p=.11, d=.23$ (see Table 3). This finding offers some support for our prediction that social scientists would score higher on this measure.

Table 3

Psychoticism by Field of Science

STEM Physical Engineering Computer Social

Psychoticism

\begin{tabular}{lccccc}
$n$ & 116 & 70 & 27 & 20 & 87 \\
$M$ & 2.90 & 2.94 & 2.74 & 2.95 & 3.08 \\
$S D$ & .86 & .72 & .86 & 1.28 & .80 \\
\hline
\end{tabular}

\section{Schizotypal Traits}

Again, we expected social scientists to score higher than STEM scientist subsets and in general on a measure of schizotypal traits. As explained above, due to the statistical difference between anthropologists and the other Social Science groups on the unusual experiences and introvertive anhedonia scales, anthropologists were not included 
in the Social Science group in these scales for the analyses that follow. Separate omnibus ANOVAs examining the effects of scientific field on schizotypal traits were not significant for unusual experiences, $F(3,193)=1.92, p>.05$, cognitive disorganization, $F(3,210)=2.08, p>.05$, introvertive anhedonia, $F(3,184)=1.36, p>.05$, or impulsive nonconformity, $F(3,207)=.76, p>.05$. However, when carrying out the single degree of freedom (planned) comparisons we found that on the cognitive disorganization scale, STEM scientists $(M=2.74, S D=2.53)$ scored significantly higher (a higher score reflects poorer attention, concentration, decision-making, and an increase in social anxiety) than social scientists $(M=2.02, S D=2.08), t(132.24)=2.12, p<.05, d=.30$ (see Table 4$)$. There was also a trend for the physical subset of STEM scientists $(M=2.78, S D=2.62)$ to score higher on the cognitive disorganization scale than the social scientists, $t(133.52)$ $=2.00, p=.05, d=.32$. Likewise, there was a trend for the computer scientists $(M=$ $3.14, S D=2.46)$ to score higher than the social scientists on this scale, $t(27.07)=1.94$, $p=.06, d=.47$ (see Table 4).

Table 4

Schizotypy Scales by Field of Science

STEM Physical Engineering Computer Social

Unusual experiences

$\begin{array}{cccccc}n & 121 & 72 & 28 & 21 & 73 \\ M & 2.11 & 2.13 & 2.14 & 2.00 & 1.40 \\ S D & 2.25 & 2.35 & 2.45 & 1.64 & 1.49\end{array}$


Table 4 (continued)

STEM Physical Engineering Computer Social

Cognitive disorganization

$\begin{array}{lccccc}n & 121 & 72 & 28 & 21 & 90 \\ M & 2.74 & 2.78 & 2.36 & 3.14 & 2.02 \\ S D & 2.53 & 2.62 & 2.39 & 2.46 & 2.08\end{array}$

Introvertive anhedonia

$\begin{array}{lccccc}n & 115 & 68 & 27 & 20 & 70 \\ M & 2.36 & 2.25 & 2.22 & 2.90 & 1.96 \\ S D & 1.87 & 1.74 & 1.55 & 2.55 & 1.86\end{array}$

Impulsive nonconformity

$\begin{array}{lccccc}n & 119 & 71 & 27 & 21 & 89 \\ M & 1.65 & 1.75 & 1.26 & 1.81 & 1.64 \\ S D & 1.57 & 1.70 & 1.46 & 1.17 & 1.47\end{array}$

Note. Anthropologists are not included in the Social Science group for the unusual experiences nor introvertive anhedonia scale statistics.

Autism Spectrum Traits

Overall $A Q$ score. Again, we expected social scientists to score higher than STEM scientist subsets and in STEM scientists in general on autism spectrum traits. As explained above, due to the statistical difference between anthropologists and the other Social Science groups on the attention switching scale of the AQ, anthropologists were not included in the Social Science group for the following analysis of the overall AQ 
score. An omnibus ANOVA was conducted yielding a significant effect of scientific field on autism spectrum traits, as measured by overall AQ score, $F(3,195)=4.06$, $p<.01$. As can be seen in Table 5 , in comparison to the social scientists $(M=16.57$, $S D=5.85)$, STEM scientists $(M=19.00, S D=17.82)$ scored significantly higher on overall AQ score, $t(192)=2.80, p<.01, d=.41$. Within the STEM sciences, the computer scientists, specifically, $(M=21.81, S D=6.88)$ scored significantly higher than the social scientists on overall AQ score, $t(192)=3.39, p<.01, d=.84$. There was a trend for the physical subset of STEM scientists $(M=18.53, S D=6.80)$ to score higher than the social scientists, although this relationship was not significant, $t(192)=1.91, p=$ $.06, d=.32$. Each of these findings supports our prediction that those in the STEM sciences would score higher than those in the social sciences on autistic traits.

Table 5

$A Q$ Scales and Overall $A Q$ by Field of Science

STEM Physical Engineering Computer Social

Social skills

$\begin{array}{lccccc}n & 118 & 69 & 28 & 21 & 88 \\ M & 3.71 & 3.61 & 3.36 & 4.52 & 3.20 \\ S D & 2.20 & 2.11 & 1.99 & 2.66 & 2.38\end{array}$

Attention switching

\begin{tabular}{cccccc}
$n$ & 116 & 70 & 25 & 21 & 72 \\
$M$ & 4.23 & 4.34 & 3.72 & 4.48 & 4.08 \\
\hline
\end{tabular}


Table 5 (continued)

STEM Physical Engineering Computer Social

$S D$

\begin{tabular}{lllll}
\hline 2.06 & 2.14 & 1.95 & 1.91 & 1.81
\end{tabular}

Attention to detail

$\begin{array}{lccccc}n & 118 & 70 & 27 & 21 & 87 \\ M & 5.07 & 5.14 & 4.89 & 5.05 & 4.51 \\ S D & 2.17 & 2.43 & 1.76 & 1.72 & 2.01\end{array}$

Communication

$\begin{array}{lccccc}n & 116 & 69 & 27 & 20 & 87 \\ M & 3.22 & 3.07 & 3.04 & 3.95 & 2.46 \\ S D & 2.04 & 2.03 & 1.81 & 2.28 & 1.93\end{array}$

Imagination

$\begin{array}{lrrrrr}n & 116 & 67 & 28 & 21 & 85 \\ M & 3.15 & 2.90 & 3.18 & 3.90 & 2.86 \\ S D & 1.83 & 1.92 & 1.68 & 1.58 & 1.83\end{array}$

Overall AQ

$\begin{array}{cccccc}n & 122 & 73 & 28 & 21 & 74 \\ M & 19.00 & 18.53 & 18.11 & 21.81 & 16.57 \\ S D & 6.57 & 6.80 & 5.23 & 6.88 & 5.85\end{array}$

Note. Anthropologists are not included in the Social Science group for the attention switching scale nor the overall $A Q$ score statistics. 
Social skills. With regards to the social skills scale, computer scientists $(M=$ $4.52, S D=2.66$ ) scored significantly higher (a higher score indicates poorer social skills) than social scientists $(M=3.20, S D=2.38), t(202)=2.39, p<.05, d=.58$. There was a trend for the STEM scientists $(M=3.71, S D=2.20)$ to score higher than the social scientists, although this relationship was not significant, $t(202)=1.74, p=.08, d=.25$. Each of these findings supports our prediction that STEM scientists would score higher than social scientists on measures of autistic traits.

Attention to detail. There was not a significant difference among the scientific fields on the attention to detail scale, $F(3,204)=1.28, p>.05$. However, there was a trend for the physical scientists $(M=5.14, S D=2.43)$ to score higher (a higher score indicates exceptional attention to detail) than the social scientists $(M=4.51, S D=2.01)$, $t(133.11)=1.76, p=.08, d=.28$. Likewise, there was a trend for the STEM scientists $(M=5.07, S D=2.17)$ to score higher than the social scientists, $t(158.25)=1.63, p=.11$, $d=.23$.

Communication. An ANOVA was conducted yielding a significant effect of scientific field on the communication scale, $F(3,202)=3.50, p<.05$. Supporting our prediction, STEM scientists $(M=3.22, S D=2.04)$ scored significantly higher than social scientists $(M=2.46, S D=1.93), t(199)=2.88, p<.01, d=.41$. Within the STEM sciences, the computer scientists, specifically, $(M=3.95, S D=2.28)$ scored significantly higher (a higher score indicates poorer communication skills) than the social scientists on the communication scale, $t(199)=3.02, p<.01, d=.75$. There was a trend for the 
physical subset of STEM scientists $(M=3.07, S D=2.03)$ to score higher than the social scientists, although this relationship was not significant, $t(199)=1.91, p=.06, d=.31$. Imagination. Supporting our prediction, computer scientists $(M=3.90, S D=$ 1.58) scored significantly higher (a higher score indicates poorer imagination) than social scientists $(M=2.86, S D=1.83)$ on the imagination scale, $t(197)=2.37, p<.05, d=.58$. There was a trend for the STEM scientists $(M=3.15, S D=1.83)$ to score higher than the social scientists on the imagination scale, although this relationship was not significant, $t(197)=1.60, p=.11, d=.23$

Scientific Profiles

At the onset of this study we wanted to create a more concise profile of scientists in each field, and that is what we have done. Figure 1 shows the specific clinical and personality characteristics examined in this study that most distinguish the profiles of each field of science. Examination of Figure 1 not only allows for the direct comparison of each of the differentiating personality and clinical scales by field of science, but the interconnected characteristics also provides a visual representation of a piece of the scientific profile that exists within each of these fields. With a more complete understanding of these factors we now have the ability to speculate about the thought and behavior of these types of scientists with greater clarity. 


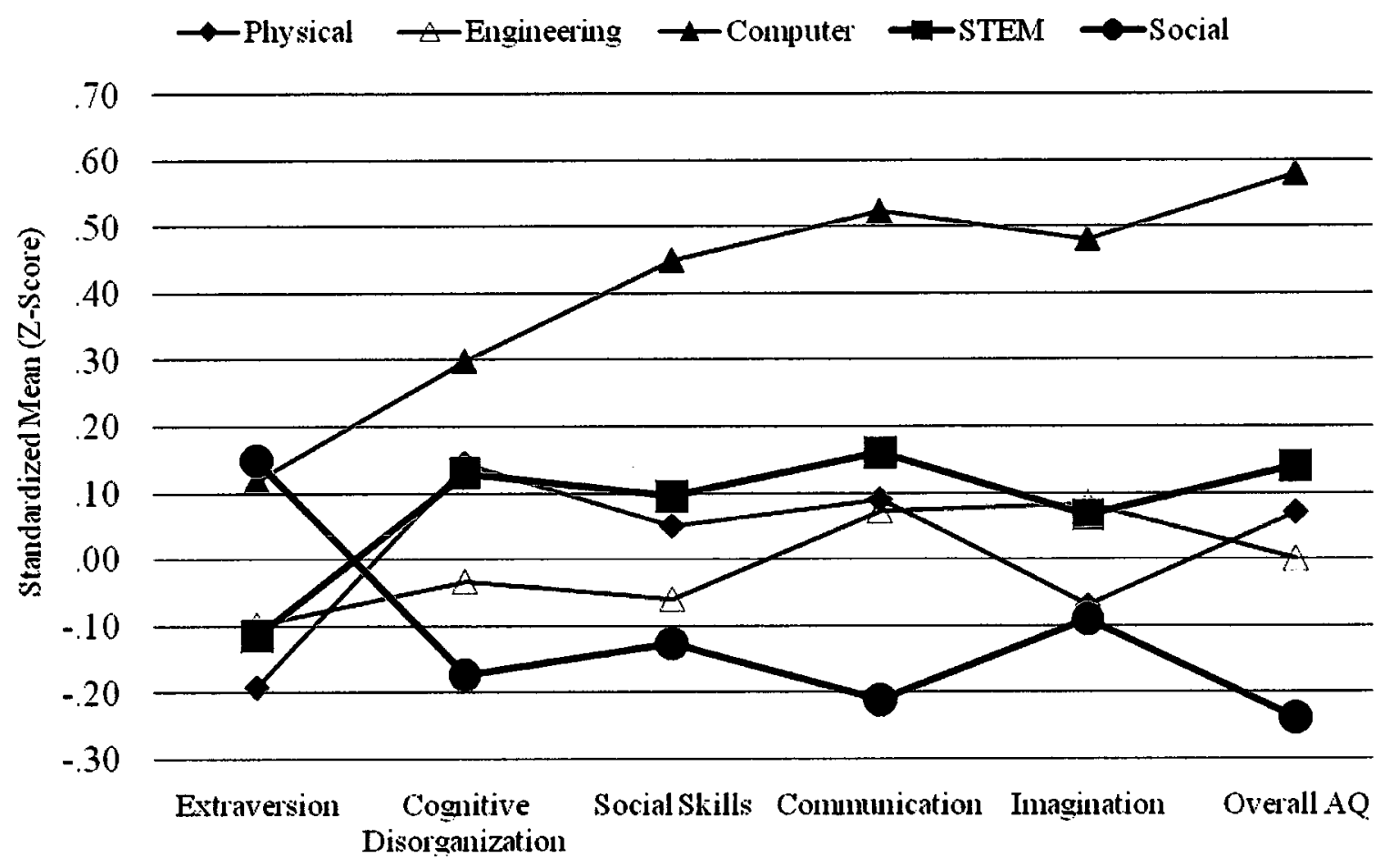

Figure 1. Standardized (z-scores) scale and overall scores by field of science contributing to scientific profiles. Anthropologists are not included in the Social Science group for overall AQ score.

Post-hoc Analyses

As with most research, some results were not predicted and were therefore posthoc. The focus of this study was mental health and the different domains of science, but the main post-hoc results concerned gender. We found that gender (male and female dummy coded as 0 and 1 , respectively) was significantly related to a number of variables. Females were higher in conscientiousness $(r=.26, p<.01)$, and lower on communication $(r=-.21, p<.01)$, imagination $(r=-.21, p<.01)$, overall AQ score $(r=-.21, p<.01)$, introvertive anhedonia $(r=-.20, p<.01)$, and cognitive disorganization $(r=-.18$, 
$p<.01)$. In order to determine whether these relationships significantly interacted with the fields of science on each of these variables, separate two-way ANOVAs were conducted for each of the abovementioned scales by gender and field of science. The only significant interaction that existed was on the communication scale of the $\mathrm{AQ}, F(3$, $202)=2.84, p<.05$, which was indicative of the linear relationship that existed on this scale between gender and field of science. There was a notable difference between the males $(M=4.73, S D=1.94)$ and females $(M=1.60, S D=1.52)$ in the computer science group, but this difference was not examined further due to an insufficient female sample size $(n=6)$. The interaction within the communication scale was taken into consideration and caution was used while interpreting all communication scale results. Likewise, due to an insufficient sample size of females within some of the fields of science, gender was not included in the above analyses but is recommended for inclusion in future research. 


\section{DISCUSSION}

\section{Scientific Profile}

The present study provides a more complete psychological profile of scientists that allows for a better understanding of the thought and behavior processes of these individuals. As hypothesized, a linear relationship was found to exist between scientists' personality and their interest or involvement in distinct domains of science. Consistent with our predictions, as well as in line with Austin (2005) and Nettle (2006), individuals in the STEM sciences do score higher than those in the social sciences, both overall, and on specific traits associated with the autism. In particular, computer scientists score higher than social scientists on autistic characteristics overall and on communication, social skill, and imagination, specifically. These results provide further evidence in support of the relationship between being thing- or people-orientated and the field of science that individuals choose to pursue.

Likewise, by supporting our prediction that social scientists are more extraverted than physical scientists, we provide additional evidence that individuals in these fields of science possess characteristics that coincide with being people- or thing-oriented, respectively. This finding is further evidence that those in specific fields of science or not only thing- or people-oriented with regards to their profession, but that the orientation is embedded in their personality profile and likely influences many aspects of their lives, including their decisions to choose one particular area of science over another.

Surprisingly, we found that STEM scientists score higher than social scientists on a measure of attentional difficulties and social anxiety (i.e., cognitive disorganization). 
These results are not consistent with Ludwig's (1998) findings that fields of science for which subjectivity, meaning, and value are emphasized tend to have a higher lifetime prevalence of psychopathology than those fields that rely on mathematics, precision, and objectivity. We were also surprised to find that no other differences existed between field of science and schizotypy.

Possible explanations for not finding any differences on the psychotic characteristics, argued by Sato (2005), are that the EPQR-A measure itself is not a sufficient or reliable method of tapping into the psychoticism dimension of personality. Sato (2005) argues that the Eysenck psychoticism scale has many psychometric issues and left it out completely when creating a new version of the EPQ. Another possible explanation for the lack of support for our predictions that social scientists would score higher than STEM scientists on both psychotic and schizotypal traits is that a difference actually does not exist. Instead, schizotypal and psychotic characteristics may be factors that make scientists as a group unique and possibly what differentiates them as a group from non-scientists. Nettle (2006) as well as Rawlings and Locarnini (2008) have conducted research in support of such a hypothesis. Both of these researchers found that scientists do tend to score lower on measures of schizotypy than do non-scientists.

\section{Implications}

The importance of having these more detailed scientific profiles is they coincide with the applications that Simonton (2009) proposes for the psychology of science in general (i.e., identification and education). He proposes that once we have the ability to identify scientific talent in individuals we may then be able to guide those individuals 
into the specific scientific domain that is most likely to maximize their potential. Simonton (2009) goes on to examine the idea that once the individual is in the most appropriate field, training within that field can then be tailored to their specific needs and learning styles. This type of tailoring is currently being explored by software developers, and as the shift continues to transpire from hardcopy to electronic textbooks, the personalization continues to get more and more specific. Baraniuk (2006) reports that software developers are just around the corner from having the ability to personalize electronic textbooks and course content to specific learning styles. In relation to the current study concerning the psychology of science, the scientific profiles that were created have the potential of being utilized by such computer software in facilitating scientific interest, talent, and achievement during education. For example, if an individual scored high on autistic characteristics, his or her textbook might then adjust to better coincide with the learning style best suited for this type of individual. Going beyond the realm of possibilities within the psychology of science, the door will also be wide open for the use of the personality and clinical measures to further tailor all textbooks, websites, cell phones, automobile features, and countless other electronic devices.

\section{Future Directions}

Future research using additional personality and clinical measures is necessary so that eventually a complete scientific profile exists. Given that previous research has supported the relationship between psychoticism and field of science (Barron, 1963; Batey \& Furnham, 2008; Kokosh, 1969; Ludwig, 1995; Nettle, 2006; Post, 1994; 
Simonton, 1999) but the current study did not, alternative measures of this personality dimension are recommended.

A limitation of the current study was the lack of a non-scientist control group. A follow-up study should be conducted in which a non-scientists sample could be examined across the abovementioned measures against the specific fields of science, and science as a whole. Another possibility would be to compare the scientific sample from the current study with non-scientist samples for each of our measures using published data. In addition, if the current study were to be replicated, it may be necessary to increase the sample size in certain fields of science and to control for the effect of gender. The psychological profile of the scientists is now more complete, but still not finished. More research is needed in the quest for a more detailed profile of scientists in general as well as particular kinds of scientists. 


\section{References}

American Psychiatric Association (2000). Diagnostic and statistical manual of mental disorders: Text revision (4th ed.). Washington, DC US: American Psychiatric Publishing, Inc.

Austin, E. J. (2005). Personality correlates of the broader autism phenotype as assessed by the Autism Spectrum Quotient (AQ). Personality and Individual Differences, $38,451-460$.

Baraniuk, (2006). Richard Baraniuk on open-source learning. Video retrieved 7/11/2009, from TED.com Web site, http://www.ted.com/talks/lang/eng/richard_baraniuk_on_open_source_learning.ht $\mathrm{ml}$

Barelds, D. P. H. \& Luteijn, F. (2002). Measuring personality: A comparison of three personality questionnaires in the Netherlands. Personality and Individual Differences, 33, 499-510.

Baron-Cohen, S., Wheelwright, S., Skinner, M., Martin, J., \& Clubley, E. (2001). 'The Autism-Spectrum Quotient (QA): Evidence from asperger syndrome/high functioning autism, males and females, scientists and mathematicians': Errata. Journal of Autism and Developmental Disorders, 31, 603.

Baron-Cohen, S., Wheelwright, S., Robinson, J., \& Woodbury-Smith, M. (2005). The Adult Asperger Assessment (AAA): A Diagnostic Method. Journal of Autism and Developmental Disorders, 35, 807-819.

Barron, F. (1963). Creativity and psychological health. Oxford England: D. Van Nostrand.

Batey, M. \& Furnham, A. (2008). The relationship between measures of creativity and schizotypy. Personality and Individual Differences, 45, 816-821.

Carnegie Foundation for the Advancement of Teaching (2008). The Carnegie Classification of Institutions of Higher Education ${ }^{\mathrm{TM}}$. Retrieved 11/13/2008 from Stanford University, The Carnegie Foundation for the Advancement of Teaching Web site, http://classifications.carnegiefoundation.org/lookup_listings/standard.php

Cohen, J. (1992). A power primer. Psychological Bulletin, 112, 155-159.

Cumella, E. J., Wall, A. D., \& Kerr-Almeida, N. 1. (2000). MMPI-2 in the inpatient assessment of women with eating disorders. Journal of Personality Assessment, $75,387-403$. 
Eysenck, H. J. (1993). Creativity and personality: Suggestions for a theory. Psychological Inquiry, 4, 147-178.

Eysenck, H. J. (1995). Genius: The natural history of creativity. New York, NY US: Cambridge University Press.

Eysenck, S. B., Eysenck, H. J., \& Barrett, P. (1985). A revised version of the Psychoticism scale. Personality and Individual Differences, 6, 21-29.

Eysenck, S. G., White, O., \& Eysenck, H. J. (1976). Personality and mental illness. Psychological Reports, 39, 1011-1022.

Feist, G. J. (1998). A meta-analysis of personality in scientific and artistic creativity. Personality and Social Psychology Review, 2, 290-309.

Feist, G. J. (2006a). The psychology of science and the origins of the scientific mind. New Haven, CT, US: Yale University Press.

Feist, G. J. (2006b). How Development and Personality Influence Scientific Thought, Interest, and Achievement. Review of General Psychology, 10, 163-182.

Feist, G. J. (2008). The Psychology of Science Has Arrived. Journal of Psychology of Science and Technology, 1, 2-5.

Feist, J. \& Feist, G. J. (2009). Theories of personality (7th ed.). New York, NY US: McGraw-Hill.

Francis, L. J., Brown, L. B., \& Philipchalk, R. (1992). The development of an abbreviated form of the Revised Eysenck Personality Questionnaire (EPQR-A): Its use among students in England, Canada, the U.S.A. and Australia. Personality and Individual Differences, 13, 443-449.

Grucza, R. A. \& Goldberg, L. R. (2007). The comparative validity of 11 modern personality inventories: Predictions of behavioral acts, informant reports, and clinical indicators. Journal of Personality Assessment, 89, 167-187.

Hogan, J., Barrett, P., \& Hogan, R. (2007). Personality measurement, faking, and employment selection. Journal of Applied Psychology, 92, 1270-1285.

Houran, J., Lange, R., Rentfrow, P. J., \& Bruckner, K. H. (2004). Do Online Matchmaking Tests Work? An Assessment of Preliminary Evidence for a Publicized 'Predictive Model of Marital Success'. North American Journal of Psychology, 6, 507-526. 
John, O. P., Donahue, E. M., \& Kentle, R. L. (1991). The Big Five Inventory-Versions 4a and 54. Berkeley, CA: University of California, Berkeley, Institute of Personality and Social Research.

John, O. P. \& Srivastava, S. (1999). The Big Five Trait taxonomy: History, measurement, and theoretical perspectives. In L.A.Pervin, O. P. John, L. A. Pervin, \& O. P. John (Eds.), Handbook of personality: Theory and research (2nd ed.) (pp. 102-138). New York, NY US: Guilford Press.

Katz, Y. J. \& Francis, L. J. (2000). Hebrew Revised Eysenck Personality Questionnaire: Short Form (EPQR-S) and Abbreviated Form (EPQR-A). Social Behavior and Personality, 28, 555-560.

Kokosh, J. (1969). MMPI personality characteristics of physical and social science students. Psychological Reports, 24, 883-893.

Kokosh, J. (1971). Two-point MMPI code types and academic achievement. Psychological Reports, 28, 671-676.

Kokosh, J. (1976). Psychology of the scientist: XXXIV. MMPI characteristics of physical and social science students: Replication and reanalysis. Psychological Reports, $39,1067-1071$.

Kusumakar, V., Bond, J., \& Yatham, L. N. (2002). Diagnosis and treatment of hypomania and mania. In L.N.Yatham \& V. Kusumakar (Eds.), Bipolar disorder: A clinician's guide to biological treatments (2nd ed.)(p. 1-18). New York, NY US: Brunner-Routledge.

Lippa, R. (1998). Gender-related individual differences and the structure of vocational interests: The importance of the people-things dimension. Journal of Personality and Social Psychology, 74, 996-1009.

Lloyd-Evans, R., Batey, M., \& Furnham, A. (2006). Bipolar Disorder and Creativity: Investigating a Possible Link. In A.Columbus \& A. Columbus (Eds.), Advances in psychology research (Vol 40) (pp. 111-141). Hauppauge, NY US: Nova Science Publishers.

Lubow, R. E. (1989). Latent inhibition and conditioned attention theory. New York, NY US: Cambridge University Press.

Ludwig, A. M. (1995). The price of greatness: Resolving the creativity and madness controversy. New York, NY US: Guilford Press.

Ludwig, A. M. (1998). Method and madness in the arts and sciences. Creativity Research Journal, 11, 93-101. 
Mason, O., Claridge, G., \& Jackson, M. (1995). New scales for the assessment of schizotypy. Personality and Individual Differences, 18, 7-13.

Mason, O., Linney, Y., \& Claridge, G. (2005). Short scales for measuring schizotypy. Schizophrenia Research, 78, 293-296.

Mason, O. \& Claridge, G. (2006). The Oxford-Liverpool Inventory of Feelings and Experiences (O-LIFE): Further description and extended norms. Schizophrenia Research, 82, 203-211.

Mount, M. K., Barrick, M. R., Scullen, S. M., \& Rounds, J. (2005). Higher-order dimensions of the big five personality traits and the big six vocational interest types. Personnel Psychology, 58, 447-478.

Nettle, D. (2006). Schizotypy and mental health amongst poets, visual artists, and mathematicians. Journal of Research in Personality, 40, 876-890.

Norman, R. D. \& Redlo, M. (1952). MMPI personality patterns for various college major groups. Journal of Applied Psychology, 36, 404-409.

Post, F. (1994). Creativity and psychopathology: A study of 291 world-famous men. British Journal of Psychiatry, 165, 22-34.

Prediger, D. J. (1982). Dimensions underlying Holland's hexagon: Missing link between interests and occupations? Journal of Vocational Behavior, 21, 259-287.

Raskin, R. \& Hall, C. S. (1981). The Narcissistic Personality Inventory: Alternate form reliability and further evidence of construct validity. Journal of Personality Assessment, 45, 159-162.

Rawlings, D. \& Locarnini, A. (2008). Dimensional schizotypy, autism, and unusual word associations in artists and scientists. Journal of Research in Personality, 42, 465471.

Roberts, B. W., Kuncel, N. R., Shiner, R., Caspi, A., \& Goldberg, L. R. (2007). The power of personality: The comparative validity of personality traits, socioeconomic status, and cognitive ability for predicting important life outcomes. Perspectives on Psychological Science, 2, 313-345.

Salgado, J. s. F. (2003). Predicting job performance using FFM and non-FFM personality measures. Journal of Occupational and Organizational Psychology, 76, 323-346.

San Diego Supercomputer (2008). National science foundation fields of science codes. Retrieved October 18, 2008, from San Diego Supercomputer Web site, http://datacentral.sdsc.edu/fos.html 
Sato, T. (2005). The Eysenck Personality Questionnaire Brief Version: Factor Structure and Reliability. Journal of Psychology: Interdisciplinary and Applied, 139, 545552.

Simonton, D. K. (1999). Origins of genius: Darwinian perspectives on creativity. New York, NY US: Oxford University Press.

Simonton, D. K. (2008). Scientific talent, training, and performance: Intellect, personality, and genetic endowment. Review of General Psychology, 12, 28-46.

Simonton, D. K. (2009). Applying the psychology of science to the science of psychology: Can psychologists use psychological science to enhance psychology as a science? Perspectives on Psychological Science, 4, 2-4.

Singh, M. \& Woods, S. A. (2008). Predicting general well-being from emotional intelligence and three broad personality traits. Journal of Applied Social Psychology, 38, 635-646.

Wakabayashi, A., Baron-Cohen, S., \& Wheelwright, S. (2006). Are autistic traits an independent personality dimension? A study of the Autism-Spectrum Quotient (AQ) and the NEO-PI-R. Personality and Individual Differences, 41, 873-883.

Widiger, T. A. (2005). Five factor model of personality disorder: Integrating science and practice. Journal of Research in Personality, 39, 67-83.

Zhang, L. f. (2002). Measuring thinking styles in addition to measuring personality traits? Personality and Individual Differences, 33, 445-458.

Zumbo, B. D. \& Taylor, S. V. (1993). The construct validity of the extraversion subscales of the Myers-Briggs Type Indicator. Canadian Journal of Behavioural Science/Revue canadienne des sciences du comportement, 25, 590-604.

Appendix 


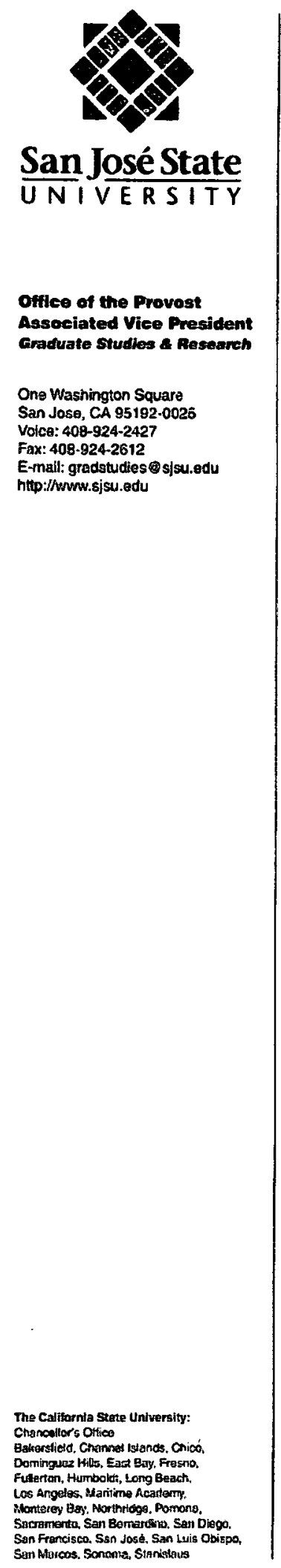

To:

Dr. Gregory Feist

Department of Psychology

San Jose State University

One Washington Square

San Jose, CA 95192-0120

Chad Kempel

From: Pamela Stacks, Ph.D.

Associate Vice President

Graduate Studies and Research

Date: October 27, 2008

The Human Subjects-Institutional Review Board has registered your study entitled:

\section{"Profile of Scientists"}

This registration, which provides exempt status under Exemption Category 2, of SJSU Policy S08-7, is contingent upon the subjects included in your research project being appropriately protected from risk. This includes the protection of the anonymity of the subjects' identity when they participate in your research project, and with regard to all data that may be collected from the subjects. The approval includes continued monitoring of your research by the Board to assure that the subjects are being adequately and properly protected from such risks. If at any time a subject becomes injured or complains of injury, you must notify Dr.

Pamela Stacks, Ph.D. immediately. Injury includes but is not limited to bodily harm, psychological trauma, and release of potentially damaging personal information. This approval for the human subject's portion of your project is in effect for one year, and data collection beyond October 27, 2009 requires an extension request.

Please also be advised that all subjects need to be fully informed and aware that their participation in your research project is voluntary, and that he or she may withdraw from the project at any time. Further, a subject's participation, refusal to participate, or withdrawal will not affect any services that the subject is receiving or will receive at the institution in which the research is being conducted.

If you have any questions, please contact me at (408) 924-2480.

Protocol \# S0804110 